\title{
Monitoring the Changing Pattern of Land Use in the Rangpur City Corporation Using Remote Sensing and GIS
}

\author{
Wahedul Islam, Subaran Chandra Sarker* \\ Department of Geography and Environmental Science, Faculty of Life and Earth Sciences, Begum Rokeya \\ University, Rangpur, Bangladesh \\ Email:"subo.ju85@yahoo.com
}

Received 17 June 2016; accepted 21 August 2016; published 24 August 2016

Copyright (C) 2016 by authors and Scientific Research Publishing Inc.

This work is licensed under the Creative Commons Attribution International License (CC BY).

http://creativecommons.org/licenses/by/4.0/

(c) (i) Open Access

\section{Abstract}

Rangpur is one of the fastest growing cities of Bangladesh with a dense population. Being the headquarter of a division in Bangladesh, it is experiencing multi-dimensional problems such as over urbanization, traffic congestion, water logging, and solid waste disposal. Rangpur is a sheer example of having poor legislative actions, inefficient management and lack of public awareness, which leads the urbanization to an unplanned and resource consuming development. This study presents an integrated study of land use pattern in Rangpur City, Bangladesh, by using Geographical Information Systems (GIS) and Remote Sensing (RS). The data sources used in this study were Landsat Thematic Mapper (TM) and a Landsat Enhanced Thematic Mapper Plus (ETM+) images taken in 1989, 2000 and 2014, respectively. All images were geometrically and radiometrically corrected and the change detection methods were performed. Then, supervised maximum likelihood classification was used as a cross classification to detect change. The study area was classified into six categories on the basis of field study, geographical conditions, and remote sensing data. The remotely detected land use change from 1989 to 2014 shows that Rangpur is gradually changing, as planted trees, open spaces, low land and Permanent water sources have been transformed into built-up areas.

\section{Keywords}

Remote Sensing, GIS, Landuse, Rangpur City Corporation

\footnotetext{
${ }^{*}$ Corresponding author.
} 


\section{Introduction}

Bangladesh is a third world country having large population. For this reason land is changing rapidly here especially in the urban area. Rangpur is a divisional city having population 0.8 million. Rapid growth of population, urbanization and development of growth centre leads to the rapid expansion of this city. For this reason the boundary of the city was expanded to $50 \mathrm{~km}^{2}$ to $203 \mathrm{~km}^{2}$ in the year of 2012 . This ultimately leads to the change of land use here. There is no credible land use related map and data of this area especially satellite image related land use data, compared to the other cities like Dhaka. Although the land use data are very much important for the proper planning. Traditional methods like surveying are long term and time consuming method for land use data collection whereas the satellite image interpretation and land use classification are simple and quick method. Landsat and other satellites provide the satellite images data from the early 1970s to present days so the land use pattern can be identified and a database can be easily made in this method using proper ways. Land use change analysis is an important tool to assess global change at various spatial-temporal scales [1]. Current and accurate information on land use is a prerequisite to the management and planning of urban areas. Satellite remote sensing data are usually the most accurate and up-to-date "map" available of developing countries. Especially with fast growing towns and cities in the developing countries, it is practically the only method that can follow up the urban growth [2]. Aerial photograph, for instance, is absolutely classified for public. For third world countries, remote sensing proved its effectiveness for spatial data updating [3] and particularly to provide accurate and timely geospatial information illustrating land use dynamics of metropolitan areas [4]. Unfortunately, no such application is available for Rangpur or its part for land use change assessment [5]. In addition, it reflects the dimension of human activities on a given environment. Change detection is the process of identifying differences in the state of an object or phenomenon by observing it at different times [6]. The remote sensing and GIS are modern techniques or tools for detecting such changes of land use by producing change map, generation of statistics of the region and analysis of the database [7]. Satellite remote sensing is a potentially powerful means of monitoring land use change at high temporal resolution and lower costs than those associated with the use of traditional methods [8].

\section{Study Area}

Rangpur City Corporation covering has an area of around 203.19 square kilometers lies on the bank of the Ghaghat River. Geographicallyis located between $25^{\circ} 38^{\prime}$ and $25^{\circ} 52^{\prime}$ North latitudes and $89^{\circ} 05^{\prime}$ and $89^{\circ} 20^{\prime}$ East longitudes (Figure 1). Rangpur City Corporation is formed of previously established Rangpur Pourasova (municipality) and 8 union of Rangpur Sadarupazila. This town was established in $16^{\text {th }}$ December 1769 during the British period and became a city corporation in 01 July, 2012. The soil composition is mainly alluvial soil (80\%) of the Teestahttps://en.wikipedia.org/wiki/Teesta_River) River [9] basin, and the remaining is barind soil. Rangpur has a tropical wet and dry climate. The climate of Rangpur is generally marked with monsoons, high temperature, considerable humidity and heavy rainfall. The population of the Rangpur city corporation as of 2014 is 865,927 , with male $50.91 \%$, female $49.09 \%$, and the literacy rate is $64.6 \%$ (BBS 2015). Rangpur city is the fifth largest city of Bangladesh after Dhaka (125 million), Chittagong 30 million), Khulna (10 million) and Rajshahi (8 million) estimated population by the 2011 census.

\section{Material and Methods}

\subsection{Materials}

The methodology adopted here for detecting land cover changes was based on the comparison between the satellite imageries of different years. Satellite imageries of Landsat TM for the year 1989, 2000 and ETM+ images of 2014 were used to assess the land use change dynamics in the study area. Spatial and radiometric characteristics of those images are given in Table 1.

Map Projection of the collected satellite images was Universal Transverse Mercator (UTM) within Zone 46 N-Datum and of the co-ordinate system World Geodetic System (WGS) 84 and the pixel size is 30 meters. For the purpose of obtaining the study area (i.e. RCC), the GIS format file (i.e. shape file) of RCC has been collected from Rangpur city corporation.

\subsection{Methods}

The collected images are pre-processed by radiometric or geometric corrections. Radiometric corrections include 
Table 1. Characteristics of used satellite data.

\begin{tabular}{ccccc}
\hline Instrument & Date of image taken & Sensors & Spatial resolution & Radiometric resolution \\
\hline Landsat-5 & January 19, 1989 & TM & 30 & 8 bit \\
Landsat-5 & November 17, 2000 & TM & 30 & 8 bit \\
Landsat-7 & March 5, 2014 & ETM+ & 30 & 16 bit \\
\hline
\end{tabular}

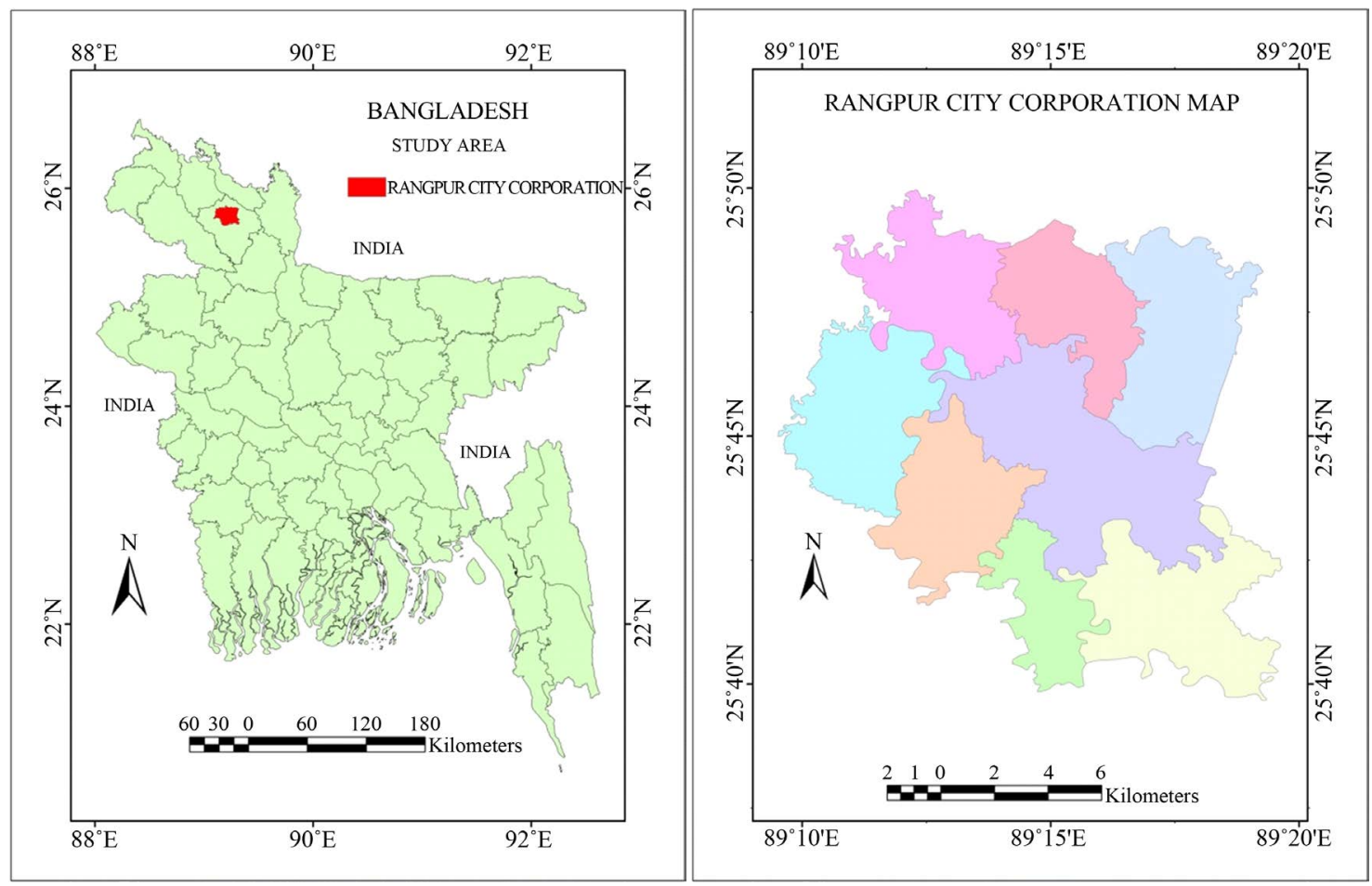

Figure 1. Study area map. Sources: Banglapedia and RCC.

correcting the data for sensor irregularities and unwanted sensor or atmospheric noise, and converting the data so they accurately represent the reflected or emitted radiation measured by the sensor. To segregate the study area from the images, geo-referencing of the satellite images have been performed. They are transformed to the Bangladesh Transverse Mercator (BTM) map projection system with datum World Geographic System (WGS) 1984 as same as the RCC shape file. Then images are clipped by Raster Processing tool under Data Management tool of ArcToolbox in ArcGIS 10.

Using the basic colors red, green and blue (RGB), it is possible to prepare different FCC images [10]. To distinguish between different cover types or ground objects like buildings, roads, and vegetation, these FCC images are useful. FCC of RGB = bands 4,3 and 2 have been chosen for this study. This combination normally makes built-up areas appear blue, planted trees red, permanent water sources from dark blue to black, soils with no planted trees from white to brown [11]. Among the other FCC images 4, 5, 3 and 5, 4, 3 combinations are used. Beyond this natural colour image or 321 combinations was used to analysis the study area.

After developing training samples for all land use classes (Table 2) the images were classified based on these training samples. This has been done using the Image Classification Toolbar in ArcGIS 10. Based on these signatures, corresponding to various land features, image classification was done using Maximum Likelihood Classification tool under Image Classification tool in ArcGIS 10.

\section{Results and Discussion}

\subsection{Results}

This study shows the changes in pattern of land user in Rangpur City Corporation. The study area witnessed 
Table 2. Details of the land use types used in this study.

\begin{tabular}{cr}
\hline Land use & Description \\
\hline Permanent water sources & River, permanent open water, lakes, ponds and reservoirs \\
Seasonal water sources & Permanent and Seasonal wetlands, marshy land, swamps. \\
Built-up area & Residential, commercial and services, industrial, transportation, roads, mixed urban, and other urban \\
Planted trees & Road side planted trees, mixed forest lands, homestead forest \\
Cultivated land & Crop fields, fallow lands and vegetable lands \\
Un-cultivated soil & Exposed soils, sand fill, landfill sites, and areas of active excavation \\
\hline
\end{tabular}

large amount of agriculture land converted into settlements and other urban development activities.

Between the periods of 1989-2014, the Rangpur city experienced a scale of land conversion unprecedented in the history of the region approximately 6502 ha area of land was converted to urban uses during this period (Table 3), an increase in urbanization. Urban areas now comprise almost 37\% (Table 3) of the study area. While approximately a quarter of the new urban areas were previously natural planted trees or water, most were converted from farmland, approximately.

Spatial patterns of land use (Figure 2) shows that urban growth followed certain directions between 1989 and 2014 depending on the ground elevation. For example, the earlier direction of the growth of built-up land was followed by centre, north-west, and south-west trends. Historically, the direction of urban expansion of Rangpur has greatly been constrained by the low elevation of lands, surrounding rivers, and flooding risk. Thus highland was subjected to major development, usually not liable to inundation. The interpretation of the 2000 and 2014 land use maps however indicated that Rangpur is being started to expand in all directions, specifically to northwest, south-west and southern parts by filling up low lying areas. Three sectors, namely, public, private and individual households are responsible for rapid land use change in Rangpur.

Unregulated expansion in Rangpur City Corporation is underway, and leading to unauthorized growth. The nature of land use changes revealed that the built-up and bare soil/landfill categories have been increased significantly (Figure 3). Figure 4 can be used to discern the incredible pressure of urbanization on natural land use in Rangpur City Corporation. Table 3 demonstrates that between 1989 and 2014, urban built-up areas increased approximately 6502 ha with a decrease of around 2235 ha in un cultivated bare soil/landfill while planted forest is decreased 406 ha, Seasonal water sources and Permanent water sources decreased 2235 ha and 1626 ha respectively. This result affirms the earlier findings made by different researchers using supervised classification by ArcGIS [12]. To accommodate the increasing population, the city has been expanded extensively compared to its early stage and concurrently its spatial expansion has been severely constrained by the physical factors. Therefore most of the development has been resulted in the loss of natural resources.

During 1989-2000, the conversion pressure was mainly onto Permanent water sources and wet land as it shows the maximum loss. But in case of 2000-2014, the pressure transferred to croplands and planted trees as most of the bare lands had already been converted to built-up areas or cultivated land (Figure 5). Urbanization in the study area has been very rapid on other land covers with discontinuous patches which resulted in diversified and uneven expansion. Inadequate housing, unplanned and haphazard development, ubiquitous urban poverty, absence of proper land use policy, inequity of lands, pitiable coordination among responsible organizations and absence of reliable information on the current land use practice, all are contributing to the urban sprawling which is leading to the unconceivable emergence of slums and squatters. The environment of slum is extremely unhygienic as they are located at sites such as solid waste dumps, open drains and sewers, embankment and often along the rail line. In addition, the people living in slums are extremely vulnerable to natural hazards such as floods. Thus the accelerated growth of slum population fosters to the loss of expensive wetlands, planted trees cover, and also negatively affecting both human and physical environments. On the contrary, the ever-increasing urban population and its poverty result in overexploitation of natural resources to a level which is no longer sustainable for future.

\subsection{Discussion}

\subsubsection{Permanent Water Sources}

Water spread area, both man-made and natural water features such as rivers, lakes, and reservoirs, also decreased 



NON-CULTIVATED BARE SOIL

BUILT UP AREA

CULTIVATED LAND

PLANTED TREES

PERMANENT WATER SOURCES

SEASONAL WATER SOURCES

Figure 2. Land use class of the study area (1989, 2000 and 2014). 

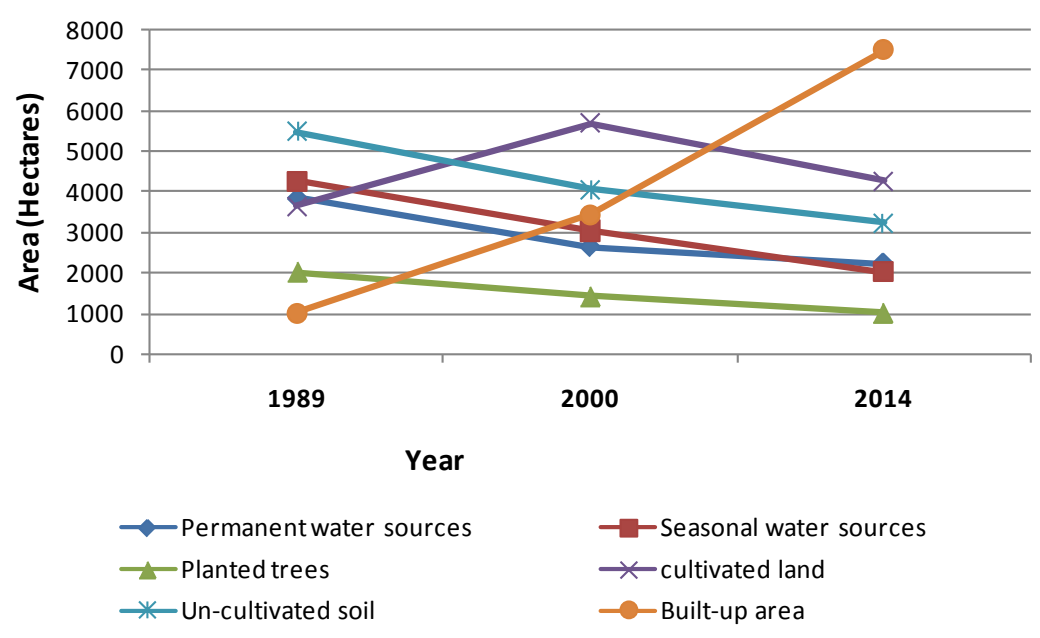

Figure 3. Temporal pattern of land use change in Rangpur city corporation.

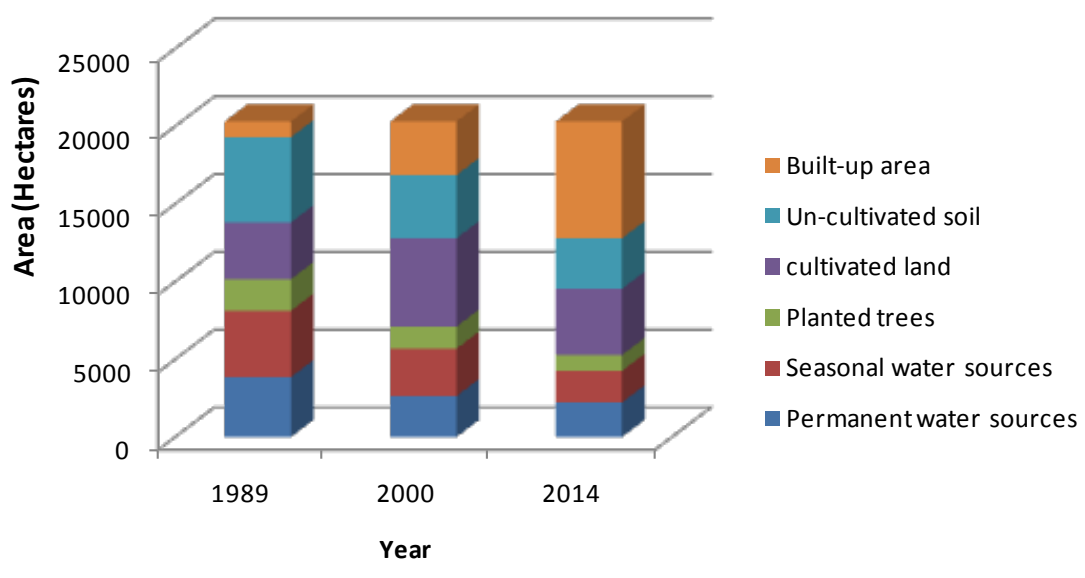

Figure 4. Relative percentage of areas during study period.

Table 3. Summary of land covers classification statistics between 1989 and 2014 (area in hectares).

\begin{tabular}{|cccccccc|}
\hline Land use & \multicolumn{2}{c}{$\mathbf{1 9 8 9}$} & \multicolumn{2}{c}{$\mathbf{2 0 0 0}$} & \multicolumn{2}{c}{$\mathbf{2 0 1 4}$} \\
\hline Land use types & Area (ha) & Percentage & Area (ha) & Percentage & Area (ha) & Percentage \\
\hline Permanent water sources & 3861 & 19 & 2641 & 13 & 2235 & 11 \\
Seasonal water sources & 4267 & 21 & 3048 & 15 & 2032 & 10 \\
Planted trees & 2032 & 10 & 1422 & 7 & 1016 & 5 \\
Cultivated land & 3657 & 18 & 5689 & 28 & 4267 & 21 \\
Un-cultivated soil & 5486 & 27 & 4064 & 20 & 3251 & 16 \\
Built-up area & 1016 & 5 & 3454 & 17 & 7518 & 37 \\
\hline
\end{tabular}

from 3861 hectares in 1989 to 2641 hectares in 2000 and 2235 hectares in 2014 with net decline of 65 hectares per year (Figure 5). Water spread area decrease is occurred due to the gradual conversion of water spread area into built-up area or human developmental area as the population increased significantly during the past decades.

\subsubsection{Seasonal Water Sources}

Various types of perennial and seasonal water sources and beels are found in the RCC. Like the Permanent water 


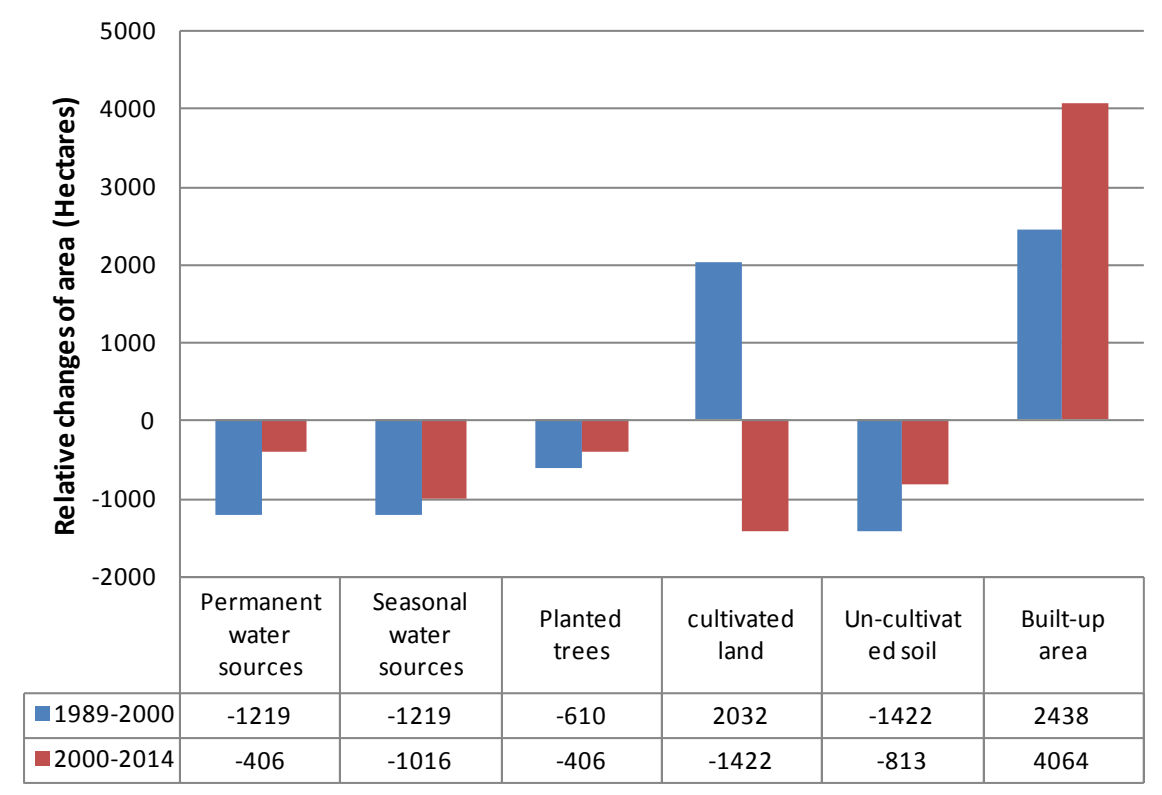

Figure 5. Relative changes of land use in RCC.

sources, wet land also decreased thought the study period. There was $21 \%$ low lying lands in 1989 , it decreased to $15 \%$ in 2000 and $10 \%$ in 2014 (Table 3). In the urban area wet lands are converted to settlement by earth filling.

\subsubsection{Planted Trees}

There is no natural or man-made forest in RCC. Home stead forest and road side trees are the main planted trees here. From the land use map (Figure 3) Planted trees shows a slow declining trend, mainly due to urbanization. This is attributed to conversion of forest lands into urban areas and other development activities. The land use maps show that all these changes occurred in the western part of the city. Most of the planted trees are found in north-eastern part of the city (Figure 2).

\subsubsection{Cultivated Land}

Agricultural practice was not prominent during 1980s, so the most of the land was remain barren. later the barren land decrease due to the conversion of non-cultivated bare soil to cultivated land. Some of the non-cultivated bare soil is converted into urban areas. Figure 2 shows the significant increasing of cultivated land between 1989 to 2000 from $18 \%$ to $28 \%$ though the rate was fallen from $28 \%$ to $21 \%$ between 2000 to 2014 . The cultivated land percent are still high albeit high rate of urbanization. This was possible due to the conversion of barren land, low lands to meet up the food demand of urban population of RCC. It noted that the most of land are capable of yielding two or three crops a year.

\subsubsection{Non-Cultivated Bare Soil}

In RCC non-cultivated bare soil denotes the sand, silt of river side and the barren land. In the early $90 \mathrm{~s}$ most of the lands are barren or grows only one crop in a year. The category of non-cultivated bare soil showed a decreasing trend from 5486 hectare to 4064 hectares between 1989 and 2000. However, a slow decreasing trend from 2000 to 2014 decelerated from 4064 to 3251, detaining an average of around 89 hectares per year. This happened mainly due to the establishment of new settlement in this city by the migrated.

\subsubsection{Built up Area}

The mixed built up land category includes settlements as well as transportation areas. It increased significantly from 1016 to 3454 hectares in 2000 then to 7518 hectares in 2014. From 1989 to 2000 the growth rate was 21\% has accelerated to around $4.28 \%$ during 2000 to 2014. Averge growth rate was $8.4 \%$. The rapid changes of urbanization causes the changes whole land use pattern of the city corporation. The growth rate during 2000 to 
2014 was more than the past; it was caused due to various reasons. Rangpur was declared divisional city in 2010 and City Corporation in 2012. These lead the rapid urbanization than before.

\section{Conclusions}

Based on the results obtained by employment of GIS and RS applications to achieve the specific research objectives, it is concluded that the land use practices in the study area have altered significantly in 26 years. The land use shift in the watershed area was evident by the decline in the area of planted trees, wet land and permanent water sources (5\%, $10 \%$ and $11 \%$ respectively) and augmentation of area covered by classes of settlements (37\%), agriculture (21\%) and barren land (16\%). The haphazard expansion of settlement and cultivated land area in the watershed was mainly due to lack of proper management and land use planning since no EIA report is generated prior to land development in the study area. The major impact of this expansion was subjected on planted trees and permanent water sources to deforestation and water depletion respectively. Additionally, all these alterations in the land use patterns adversely affected water quality and accessibility by 2014 which may prove a limiting factor in the future for both urban growth and agriculture practice and may also be responsible for further loss of already shrinking planted trees cover in this area. Hence, proper management of these water resources is required because without proper management, this valuable water resource will soon be lost or will no longer be able to play its required role in agriculture production and socio-economic development of the area. Having said all that, there are several recommendations based upon the conclusion of the present study for the proper management and conservation of the forest, water and soil resources subjected to decline in the watershed.

It is hoped that the methodology adopted for this study could be extended towards more across the region.

\section{Acknowledgements}

I would like to express my deep sense of gratitude to my supervisor for his valuable suggestion and continuous help. Without his guidance and supervision I would not be able to complete the work timely. I thank to SPARRSO authority for supplying the appropriate image. I also thank Bangladesh Meteorological Department.

\section{References}

[1] Lambin, E.F. and Geist, H.J. (2006) Land Use and Land Cover Change-Local Processes and Global Impacts. Springer Publication, 222.

[2] Pellikka, P., et al. (2004) Land Use Change Monitoring Applying Geographic Information Systems in the Taita Hills, SE-Kenya. Proceedings of the 5th African Association of Remote Sensing of Environment Conference, Nairobi, 17-22 October 2004.

[3] Dong, Y., Forster, B. and Ticehurst, C. (1997) Radar Backscatter Analysis for Urban Environments. International Journal of Remote Sensing, 18, 1351-1364. http://dx.doi.org/10.1080/014311697218467

[4] Yang, X. and Lo, C.P. (2002) Using a Time Series of Satellite Imagery to Detect Land Use and Cover Changes in the Atlanta, Georgia. International Journal of Remote Sensing, 23, 1775-1798. http://dx.doi.org/10.1080/01431160110075802

[5] Dewan, A.M. and Yamaguchi, Y. (2009) Using Remote Sensing and GIS to Detect and Monitor and Use and Land Cover Change in Dhaka Metropolitan of Bangladesh during 1960-2005. Environmental Monitor Assessment, 150, 237 249. http://dx.doi.org/10.1007/s10661-008-0226-5

[6] Li, Z.L., et al. (2012) Advances in Photogrammetry, Remote Sensing and Spatial Information Sciences. ISPRS Congress Book, CRC Press, New York, 227.

[7] Das, S.C. and Husnaien, N. (2008) Monitoring Land Use Changes in the North-Eastern Part of Sundarban Using Remote Sensing and GIS Techniques. Journal of the Bangladesh National Geographic Association, 365, 99-109.

[8] Belal, A.A. and Moghanm, F.S. (2011) Detecting Urban Growth Using Remote Sensing and GIS Techniques in Al Gharbiya Governorate, Egypt. The Egyptian Journal of Remote Sensing and Space Science, 14, 73-79. http://dx.doi.org/10.1016/j.ejrs.2011.09.001

[9] Teesta River (2014) https://en.wikipedia.org/wiki/Teesta_River

[10] Eastman, J.R. (2009) IDRISITaiga Tutorial (Manual Version 16.02). Clark Labs, Clark University, Massachusetts. 
[11] Geospatial Data Service Centre (2008)

http://gdsc.nlr.nl/gdsc/information/earth_observation/band_combinations

[12] Hassan, M.S. and Mahmud, S. (2013) Urban Area Change Analysis in the Rangpur Sadar Upazila, Bangladesh Using Landsat Imageries. International Journal of Science and Research (IJSR), 4, 469-474.

\section{Submit or recommend next manuscript to SCIRP and we will provide best service for you:}

Accepting pre-submission inquiries through Email, Facebook, LinkedIn, Twitter, etc.

A wide selection of journals (inclusive of 9 subjects, more than 200 journals)

Providing 24-hour high-quality service

User-friendly online submission system

Fair and swift peer-review system

Efficient typesetting and proofreading procedure

Display of the result of downloads and visits, as well as the number of cited articles

Maximum dissemination of your research work

Submit your manuscript at: http://papersubmission.scirp.org/ 